\title{
Tumoral Calcinosis and Epidural Lipomatosis of the Lumbar Spine
}

\section{Lomber Omurgada Tümoral Kalsinoz ve Epidural Lipomatoz}

\author{
Selin TURAL EMON ${ }^{1}$, Suheyla UYAR BOZKURT², Arzu GERCEK ${ }^{3}$ Serdar OZGEN ${ }^{4}$ \\ ${ }_{1}^{1}$ Academic Hospital, Department of Neurosurgery, Istanbul, Turkey \\ ${ }^{2}$ Marmara University, Faculty of Medicine, Department of Pathology, Istanbul, Turkey \\ ${ }^{3}$ Acıbadem University, Faculty of Medicine, Department of Anesthesiology and Reanimation, Istanbul, Turkey \\ ${ }_{4}^{4}$ Acibadem University, Faculty of Medicine, Department of Neurosurgery, Istanbul, Turkey
}

Correspondence address: Selin TURAL EMON / E-mail: turalselin@gmail.com

\begin{abstract}
Lumbar spinal tumoral calcinosis and spinal epidural lipomatosis are rare conditions. We present a 70-year-old female patient with serology negative spondyloarthropathy who developed paresis due to tumoral calcinosis in the left facet joint between L5 and S1 levels and spinal epidural lipomatosis at L5 and S1 levels. Surgery was performed to excise the lesions en bloc. Neural decompression was provided. Neurological symptoms improved after surgery. Here, we report the first serology negative spondyloarthropathy case that had concomitant development of tumoral calcinosis and spinal epidural lipomatosis.
\end{abstract}

KEYWORDS: Tumoral calcinosis, Spinal epidural lipomatosis, Serology negative spondyloarthropathy, Radiculopathy

öz

Lomber spinal kalsinoz ve spinal epidural lipomatoz seyrek görülen durumlardır. L5 ve S1 sol faset ekleminde tumoral kalsinozise ve epidural lipomatozise bağlı olarak parezi gelişen seronegatif negatif spondiloartropatili 70 yaşında bir kadın hasta sunulmaktadır. Cerrahi tedavi uygulandı ve lezyonlar bütünüyle çıkartıldı. Nöronal dekompresyon sağlandı. Burada ilk defa tumoral kalsinoz ve spinal epidural lipomatozin birlikte görüldüğü seronegatif spondiloartropati olgusu sunulmaktadır.

ANAHTAR SÖZCÜKLER: Tümoral kalsinoz, Spinal epidural lipomatoz, Seroloji negatif spondiloartropati, Radikülopati

\section{INTRODUCTION}

Tumoral calcinosis was first described by Inclan et al. (4) in 1943. Tumoral calcinosis (TC) is a relatively rare disorder, most commonly seen in people of African descent. The etiology is uncertain, but manifestations are often apparent by the second decade of life, affecting the hips most frequently, then buttocks, elbows and smaller joints. The histological appearance is characterized by densely loculated masses of calcified debris and fluid enclosed by fibrous tissue. Lesions grow quite slowly and rarely cause pain unless there is nerve involvement. Surgical removal is the treatment of choice. Incomplete resection leads to recurrence.

Tumoral calcinosis involving the lumbar spine is rare; to our knowledge, only 9 studies on lumbar tumoral calcinosis have been reported in the literature $(1,2,7,8,9,11,13,14,15)$. The lesions involved the vertebral bodies, facet joints, dura, and filum terminale $(1,2,8,9)$. Scleroderma, systemic sclerosis, and CREST (calcinosis, Raynaud phenomenon, esophageal dysmotility, sclerodactyly, and telangiectasia) syndrome may be the underlying disorders $(7,9,12,14)$. Vertebral disc and facet joint degeneration can be the cause of tumoral calcinosis in the spine (2). Spinal epidural lipomatosis (SEL) is a pathological fat tissue overgrowth in the vertebral canal. It is a rare complication of chronic steroid therapy. The prevalence of SEL is unknown. It has been reported with hypothyroidism, morbid obesity, anabolic steroid and exogenous glucocorticoid administration and endogenous hypercortisolism (5). In all these patients, the development of SEL was independent of glucocorticoid dose (5). It can be the cause back pain and radiculopathy. Epidural adipose tissue with a thickness greater than $7 \mathrm{~mm}$ is a diagnostic criterion for SEL (3). SEL commonly involves thoracic level.

In this case report we present the co-existence of two rare conditions; lumbar tumoral calcinosis and spinal epidural lipomatosis in a patient having serology negative spondyloarthropathy.

\section{CASE REPORT}

A 70-year-old female patient presented with low back and left leg pain. Neurological examination revealed hypoesthesia in the left-sided S1 dermatome and hypoactive Achilles reflex. Straight leg-raising test was positive on the left at 30 degrees. Extensor hallucis longus muscle strength was $4 / 5$ (Medical Research Council (MRC) scale for muscle strength). Serology 
negative spondyloarthropathy had been diagnosed 6 years before. The patient had since been treated with medications. Her medical treatment consisted of $5 \mathrm{mg}$ prednisone daily and $10 \mathrm{mg}$ methotrexate once a week.

\section{Laboratory and diagnostic imaging studies}

Blood workup revealed normal serum calcium and phosphorus levels with no abnormalities in renal function.

Preoperative plain radiography did not show any calcifying lesions at the facet joints. It showed moderate spondylotic changes. Magnetic resonance imaging showed significant facet joint degeneration on the left L5-S1 and originating from this facet joint, a lesion of $8 \mathrm{~mm}$ in compressing the left L5 root. This lesion was hypointense on T1-T2 weighted images. Magnetic resonance imaging revealed synovial cyst for this lesion. Second lesion was at the L5-S1 level and located on the left side of the dural sac. This lesion was hyperintense on T1-weighted images. Magnetic resonance imaging diagnosis was epidural lipomatosis for this lesion (Figure 1,2,3).

\section{Histological examination}

Histopathological examination showed amorphous calcified foci of various sizes surrounded by fibrous granulomatous tissue. Infiltrations of histiocytes were observed. Tumoral calcinosis and lipomatosis were diagnosed (Figure 4).

\section{Treatment}

The left L5-S1 facet joint was exposed. L5 hemilaminotomy was performed, and TC and SEL were removed totally. Adequate neural decompression was achieved. The patient's

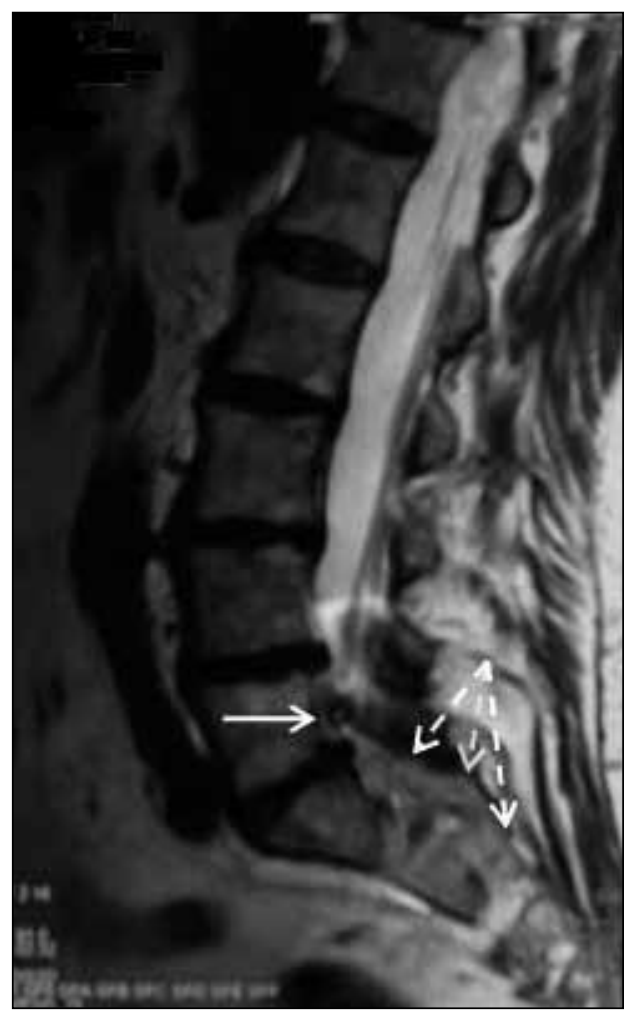

Figure 1:

T2-weighted parasagittal MRI scan showing a mass posterior to the spinal canal associated with the posterior elements (arrow). Preoperative diagnosis was a synovial cyst. Epidural lipomatosis in the spinal canal (dotted arrows).

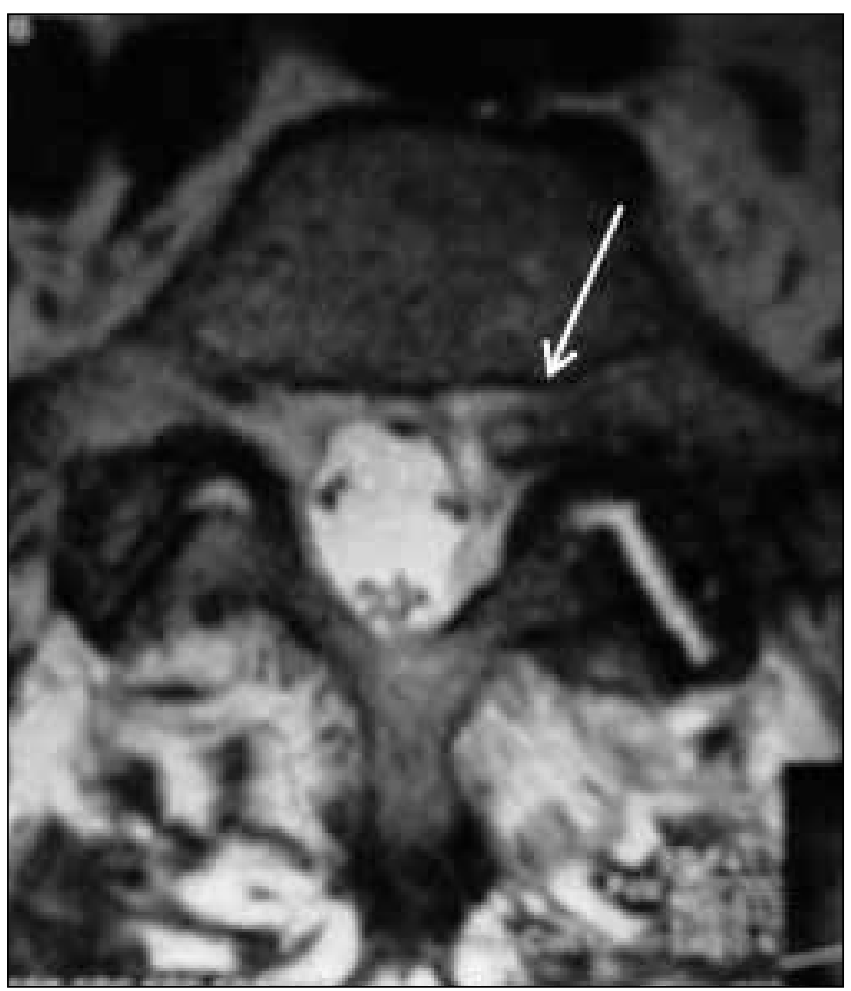

Figure 2: T2-weighted axial MRI scan showing an extradural rounded mass associated with the posterior elements.

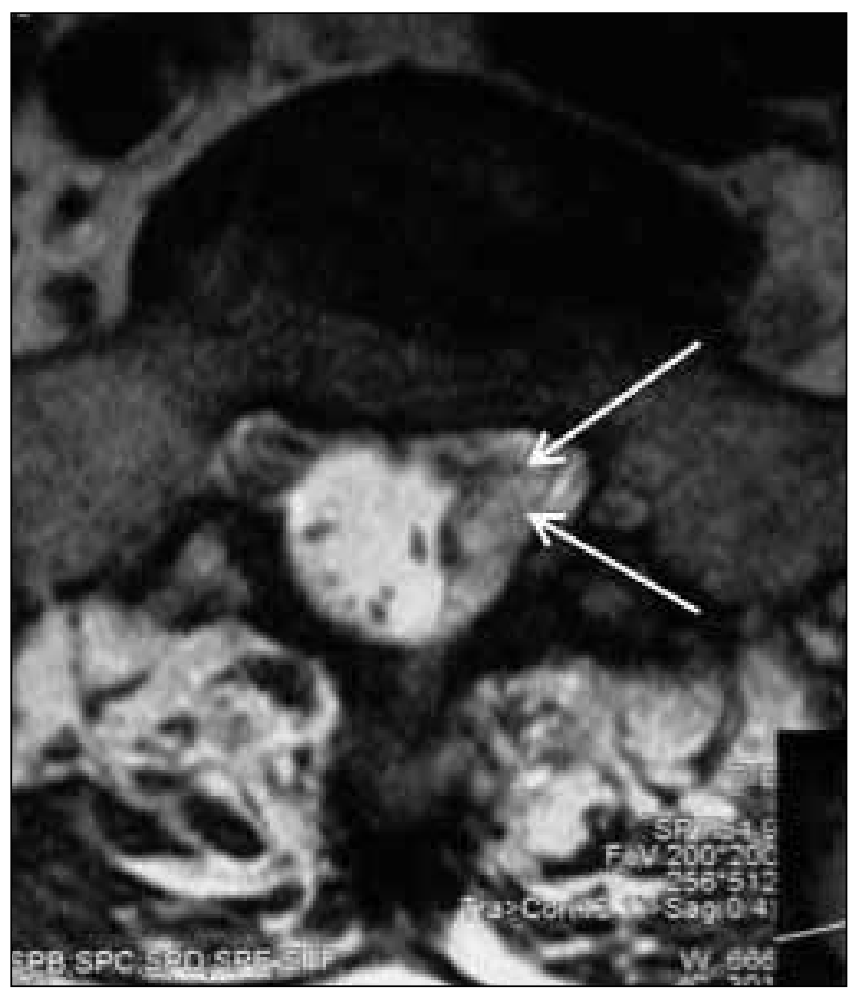

Figure 3: T2-weighted axial MRI scan showing spinal epidural lipomatosis. It is compressing the dural sac and nerve root. 


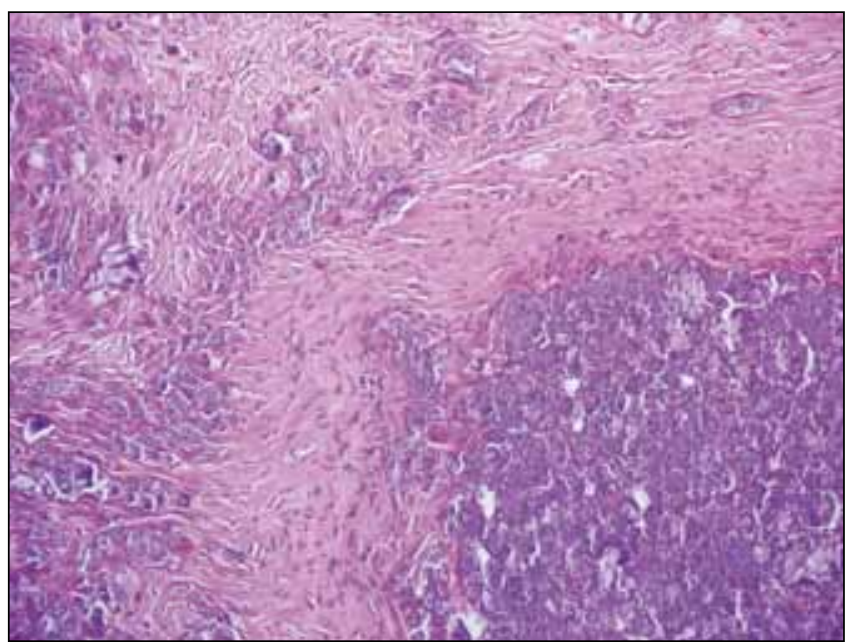

Figure 4: Amorphous calcified material surrounded by fibrous tissue and histiocytes (Hematoxylin and eosin; magnification $\mathrm{x} 200)$.

low-back pain and lower-extremity pain resolved completely after the surgery. Muscle strength was improved.

\section{DISCUSSION}

Lumbar spinal tumoral calcinosis and spinal epidural lipomatosis are rare conditions. Reimenschneider and Ecker (11) reported the first case of lumbar tumoral calcinosis in 1952. Smack et al. (10) reviewed 121 cases of TC and classified them into three types: Type 1 is characterized by normal serum phosphate and normal serum calcium levels, and no evidence of metabolic abnormality or genetic association; Type 2 is characterized by elevated serum phosphate but normal serum calcium levels, and a genetic association; and Type 3 calcinosis is associated with concurrent underlying diseases capable of causing soft tissue calcification, such as chronic renal failure, hyperparathyroidism, scleroderma, and malignant tumor. Our patient had concurrent unidentified serology negative spondyloarthropathic connective tissue disease, and the calcinosis type of the patient was probably type 3. Few cases of tumoral calcinosis due to scleroderma have been reported $(4,8,11)$. Durant et al. (2) studied 21 patients with tumoral calcinosis. In 12 of these 21 patients, the lesions were seen in the lumbar spine. In 5 of these lumbar spinal TC patients' preoperative diagnosis was synovial cyst. Similarly, in our patient, our preoperative diagnosis was synovial cyst for the lesion originating form the L5-S1 facet joint. Symptomatic SEL has been associated with exogenous steroid use in approximately $75 \%$ of the patients (6). SEL may cause radiculopathy in chronic steroid therapy in patients with serology negative spondyloarthropathy. The primary treatment of SEL is loss of weight, and decompressive laminectomy might be performed if it causes severe neurological deficit (5). We performed laminotomy and excised the epidural fat. Incomplete resection of TC has been associated with recurrence; thus, this is a very important point for preoperative diagnosis for patients with serology negative spondyloarthropathy. Tumoral calcinosis and lipomatosis should be considered in the differential diagnosis of spinal lesions in serology negative spondyloarthropathic patients. The spine should be evaluated for potential tumoral calcinosis and spinal epidural lipomatosis in the presence of low-back and leg pain, neurological dysfunction, and symptoms and signs suggesting compression of the spinal cord. The treatment should be planned depending on the neurological status of the patient. Misdiagnosis of cases with tumoral calcinosis is common. We should suspect this condition in case of cysts arising from the facet joint in serology negative spondyloarthropathic connective tissue disease patients. The risk of tumoral calcinosis recurrence should therefore also be kept in mind in the decision making process for the surgical treatment of serology negative spondyloarthropathy. The presence of these disorders should warn the surgeon regarding a more radical excision.

\section{REFERENCES}

1. Blay P, Fernández-Martínez JM, Díaz-López B: Vertebral involvement in hyperphosphatemic tumoral calcinosis. Bone 28:316-318, 2001

2. Durant DM, Riley LH 3rd, Burger PC, McCarthy EF: Tumoral calcinosis of the spine: A study of 21 cases. Spine 26:1673-1679, 2001

3. Gupta R, Kumar AN, Gupta V, Madhavan SM, Sharma SK: An unusual cause of paraparesis in a patient on chronic steroid therapy. J Spinal Cord Med 30:67-69, 2007

4. Inclan A, Leon P, Camejo MG: Tumoral calcinosis. JAMA.121: 490-495, 1943

5. Koch CA, Doppman JL, Patronas NJ, Nieman LK, Chrousos GP: Do glucocorticoids cause spinal epidural lipomatosis? When endocrinology and spinal surgery meet. Trends Endocrinol Metab 11:86-90, 2000

6. Kotilainen E, Hohenthal U, Karhu J, Kotilainen P: Spinal epidural lipomatosis caused by corticosteroid treatment in ulcerative colitis. Eur J Intern Med 17:138-140, 2006

7. Nagai $Y$, Sogabe $Y$, Ishikawa O: Tumoral calcinosis of the ribs and lumbar spine in systemic sclerosis. Eur J Dermatol 18:473-474, 2008

8. Sharma M, Sinha R, Hussey K, Fouyas IP: Tumoral calcinosis of the filum terminale. Neurosurgery 57:E596, 2005

9. Shibuya S, Kawaguchi Y, Arima N, Yamamoto T, Dobashi H, Tokuda $M$ : Tumoral calcinosis in bilateral facet joints of the lumbar spine in scleroderma. Case report. J Neurosurg Spine 5:451-454, 2006

10. Smack D, Norton SA, Fitzpatrick JE: Proposal for a pathogenesisbased classification of tumoral calcinosis. Int J Dermatol 35: 265-271, 1996

11. Reimenschneider PA, Ecker A: Sciatica caused by calcinosis;a case report. J Neurosurg 9:304-307, 1952

12. Teng $A L$, Robbin MR, Furey CG, Easley SE, Abdul-Karim FW, Bohlman $\mathrm{HH}$ : Tumoral calcinosis in the cervical spine in a patient with CREST syndrome. A case report. J Bone Joint Surg Am 88:193-197, 2006

13. Vaicys C, Schulder M, Singletary LA, Grigorian AA: Tumoral calcinosis of the lumbar spine. Case illustration. J Neurosurg 91:137, 1999

14. Ward $M$, Curé J, Schabel $S$, Smith EA, Schumacher HR Jr, Silver RM:Symptomatic spinal calcinosis in systemic sclerosis (scleroderma). Arthritis Rheum 40:1892-1895, 1997

15. Watanabe $A$, Isoe $S$, Kaneko $M$, Nukui $H$ :Tumoral calcinosis of the lumbar meninges: Case report. Neurosurgery 47:230-232, 2000 